\title{
MITIGATION OF CURRENT HARMONIC DISTORTIONS STREAMING FROM DOMESTIC NON-LINEAR LOADS USING SINGLE PHASE ACTIVE POWER FILTER.
}

\author{
NDUNGU1* ${ }^{*}$ C., NDERU1, J., NGOO², L., \& HINGA ${ }^{1}$, P. \\ ${ }^{1}$ Jomo Kenyatta University of Agriculture and Technology. P. O Box 6200 - 00200 Nairobi. \\ ${ }^{2}$ Multimedia University of Kenya, P. O Box 15653 - 00503, Nairobi, Kenya.
}

Received January 2018; $\quad$ Revised March 2018; $\quad$ Accepted April. 2018

\begin{abstract}
This study investigated current harmonic distortions emanating from domestic non-linear loads which have adverse deleterious effects on installed low voltage switchgears such as transformers and conductors. The study examined harmonic distortions emanating from dominant domestic nonlinear loads such as microwave, TV set, radio, fridge, video player and compacted fluorescence bulbs (CFLs) using a power quality equipment. From the results obtained, it was noted that there is need to mitigate harmonic distortions generated by domestic loads at point of common coupling (PCC). It is pertinent to mention that the recent study on supplied loads carried out in Kenya power grid shows that above $67 \%$ of power end users are domestic consumers. Under current last mile initiative and Global Partnership on Output Based Aid (GPOBA), unprecedented increase of domestic loads connected to the power grid is predicted. It is worth pointing out that most of these domestic loads have switch mode power supplies (SMPS) which have inherent characteristics of distorting current waveform which causes voltage distortions, over-heating of neutral conductors and premature failure of distribution transformers. Further, most of these loads have two modes; standby/sleep mode and operating mode. Results shows that the two modes generate current harmonic distortions which stream back to power utility network through the service cable. Recently, engineers have designed electronic devices that consume less power. These devices draw current in pulses rather than sinusoidal waveform. As a result, the quality of power supplies continues to deteriorate hence adversely affecting the installed low voltage switchgears such as distribution transformers. Although various mitigation measures exist to reduce the effects of harmonic distortions, this paper proposes a single phase active filter as an optimal solution for attenuating the harmonics emanating from domestic non-linear loads.
\end{abstract}

Keywords: Current harmonic distortions, active filter, distribution transformer, passive filter

*Correspondence to: Ndungu, C: Jomo Kenyatta University of Agriculture and Technology. P. O Box 6200 - 00200, Nairobi. Email: cndungu03@yahoo.com

\section{INTRODUCTION.}

The power quality in recent time has attracted unprecedented attention due to modern equipment being sensitive to power perturbations. Most of the modern equipment have electronic components whose main objective is to reduce the power usage and increase power consumption efficiency. However, their non-linear characteristics and nature, distort the current waveform. This non-sinusoidal current waveform is the main area the researchers are investigating to tame their profound effects on the power system. The findings from research 


\section{Journal of Applied Sciences, Engineering and Technology for Development. Volume 2, Issue 1}

carried out by Eaton (2012), revealed that harmonics in electrical system have been widespread due to harmonic-producing loads in recent years. In this regards, it has become necessary to address their influence when making any addition or changes to a low voltage installation. This is because, additional equipment can attenuate or worsen the harmonic distortions as succinctly noted by Hussein, et al., (2010). Alberto, et al., (2012) noted that mitigating the system harmonics is a crucial task in order to minimize system losses, increase utility revenues and prevent undesirable effects of harmonics to the connected loads. Adverse effects of harmonics are numerous when harmonic distortions are significant in the power system. They are known to cause heating of neutral conductor, over-loading of the transformers, wrong energy measurement by energy meters and erroneous tripping of the circuit breakers. Ndungu, et al., (2012) found out that harmonic distortions cause the large power consumers to pay high electricity bill due to high apparent power (kVA) and power factor surcharge due to low total power factor as depicted in equations:

Total Power factor $(\mathrm{TPF})=$ Displacement Power Factor $(\mathrm{DPF}) *$ Distortion factor $(\mathrm{DF})$

Where DPF $=\operatorname{Cos} \theta$

Where $\theta$ is $\tan ^{-1} \theta=\frac{\text { Reactive power }(\text { Var })}{\text { Actual power }(W)}$

$\mathrm{DF}=1$ for linear load and $<1$ for Non-linear loads $=\frac{1}{\sqrt{1+T H D^{2}}}$

Apparent power $=\frac{\text { Real Power }(W)}{T P F}$

Power factor surcharge is given by

$$
=(\text { cost of units }+ \text { cost of } k V A) \times(2 \%)\left(\frac{0.90-P F}{0.9 \times 0.01}\right)
$$

Prachi (2008), highlighted the importance of operating within the imposed harmonic limits and recommended practices and design so that the harmonic distortions levels are kept in check. There are various international standards such as IEEE 519, EN 61000-2-3, IEC 10003-2 and ER G5/4 which have imposed stringent requirements which manufacturers and power users need to adhere to in order to limit the level of harmonics in power system. To comply with these harmonic standards, this study consedered various existing and upcoming mitigating techniques employed to limit the levels of current distortions at point of common coupling. This research was motivated by high level of harmonic distortions in low voltage system and high premature failure of distribution transformers. Recent studies on connected loads on power grid revealed that above $67 \%$ of connected loads are domestic loads. Reports from Kenya Power and Lighting Company annual performance show that domestic consumer's growth precedes other categories of consumers (commercial and industrial power users) as shown in the Figure 1. 


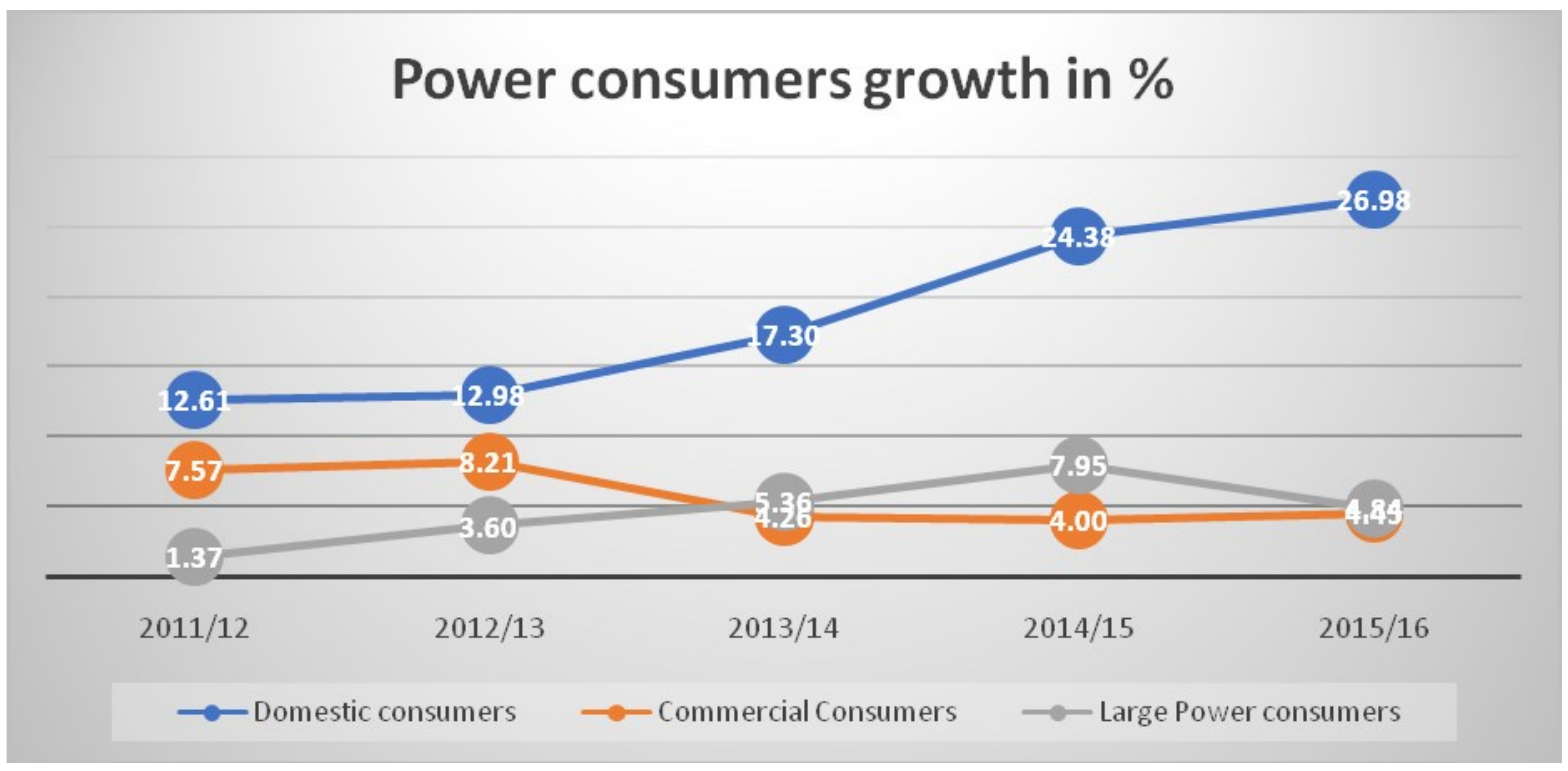

Figure 1: Growth of categories of power consumers in Kenya. Source: KPLC 2016 annual report

From Figure 1, it is evidence that there is a sharp increase of domestic consumers while the numbers of large power consumers have declined. In addition, the growth of commercial consumers has stagnated. On the other hand, transformers failure rate has been cited at $12 \%$ annually (KPLC network performance report, 2016). For this reason, due to emerging power quality issues on low voltage network, innovative and cost-effective methods of mitigation of current harmonic distortions are paramount. It has been noted that, there has been an upsurge of domestic electronics in modern society connected into the low voltage network which are usually non-linear in nature. This study examined harmonic distortions emanating from dominant domestic nonlinear loads. Active harmonic filters have been singled out as ideal for mitigating current harmonic distortions emanating from modern domestic equipment to curb vitiation of distribution transformers currently occuring on low voltage network.

Literature reveals there are numerous methods employed to eliminate or attenuate the level of harmonic distortions on power system. Some of the main ones include the following:

\section{Passive filter}

Passive filter consists of passive elements; inductor, capacitor, memristor, and resistors. They are simple to design and implement. They are usually connected as shunt to sink the harmonic frequencies or series to block the harmonic streaming back to the power network. Passive filter can be single tuned, $1^{\text {st }}$ order high-pass, $2^{\text {nd }}$ order high pass or $3^{\text {rd }}$ order high pass. The choice of the filter to install depends on observed dominant frequencies at PCC. Passive filters are bulk and are known to cause dangerous resonance with line impedance, and only mitigate specific frequencies. Passive filters are the cheapest method of mitigating current harmonic distortions although they are affected by ambient temperature.

\section{K-Factor transformer}

The amount of harmonics produced by a given load is represented by the term ' $\mathrm{K}$ ' factor. The higher the ' $\mathrm{K}$ ' factor the higher the harmonics present, hence the more harmonic current the transformer must be designed to survive. Distribution transformers with $\mathrm{K}$ - factor have been in use since 1990. The $\mathrm{K}$-factor is given as; 


$$
\text { K-factor } \quad=\quad \sum I_{h}{ }^{2} h^{2}
$$

Where; $I_{h}=\%$ current of harmonic $h, h=$ Harmonic odd order; $3^{\text {rd }}, 5^{\text {th }}, 7^{\text {th }}$,

A linear load has $\mathrm{K}$ - factor of 1 . The higher the $\mathrm{K}$-factor, the higher the ability of a transformer to withstand the additional heating generated by the harmonic current. The higher the K-factor the transformer is, the higher its cost. Standards recommend K- factor ratings of $4,9,13,17,20,30,40$ and 50. Some of the K-Factor designed transformer applications as per the Claude Lyons Group, transformer manufacturer, include;

K-1 Resistance heating, motors, control transformers (THDi<5\%).

K-4 Welders, induction heaters, fluorescent lighting, solid state controls $(T H D i<35 \%)$.

K-13 Telecommunications equipment $(T H D i<75 \%)$.

K-20 Main frame computers, variable speed drives, sub circuits with loads of data processing equipment, desktop computers $(T H D i<100 \%)$.

\section{Low harmonic devices}

Low harmonic devices have front - end rectifier that employs forced - commutated devices such as IGBTs, MOSFET, GTO and IEGT (injected-enhanced gate transistor) rather than natural commutated electronic devices such as diodes or thyristor (commonly referred as natural commutation) for $\mathrm{AC} / \mathrm{DC}$ power conversion.

\section{De-rating power equipment}

De-rating equipment implies uprating the equipment. This translates in more cash outlay and longer payback period of initial capital investment. De-rated equipment can carry additional loading (increased $I_{r m s}$ ) caused by presence of harmonic as shown in equation (7) below;

$$
\mathrm{I}_{\mathrm{r} . \mathrm{m} . \mathrm{s}}=\sqrt{1+T H D_{i}^{2}}
$$

High harmonic distortions (current) causes $\mathrm{I}_{\mathrm{rms}}$ to increase significantly hence resulting to over-loading of installed switchgears such as transformers, cables, and conductors. Overloading impacts negatively on performance of the equipment and diminish life expectancy of the installed equipment.

\section{Active harmonic power filter}

Active Power filter is the latest technology employed to reduce transient phenomena, harmonic distortions, improve the dynamic of the reactive compensation and system imbalances. One of the major advantage of Active Harmonic Power Filter (AHPF), which has made it more preferred in most of installation, is that it does not cause harmful resonance with the power distribution system impedance. AHPF acts as a controlled current generator that compensates the harmonic current, so that the source current drawn from the power utility network is sinusoidal and in phase with the system voltage (has unity power factor). Active power filters are categorized by the mode of connection at the PCC. The configuration depends on interfacing inductor (shunt AHPF) or transformer (series AHPF). The AHPF can be hybrid (combination of APF and passive filter) or power quality line conditioner (combination of shunt and series AHPF). 
Journal of Applied Sciences, Engineering and Technology for Development. Volume 2, Issue 1

\section{METHODS}

Harmonic distortions emanating from domestic non-linear loads were investigated using a power quality analyser (PQA) at the point of common coupling (at domestic premise energy metering point). Each appliance was powered individually and current harmonic distortions recorded. This study also powered combination of different loads and repeated the same procedure. At least for two of each type of devices, the harmonic distortions were obtained and their average THDi calculated. Further, the researchers sampled transformer oil and harmonic levels were investigated on the low side of the distribution transformer. The sampled oils were taken to high voltage laboratory where breakdown voltage (BDV) was tested on each sample using a BDV machine. For each sample, ten (10) BDV tests were done and an average value was automatically generated by the oil dielectric strength testing equipment. The oil containers were tight sealed to avert moisture ingression so that the results were not compromised. Oil colour was also observed for every oil sample. Figure 2 present the PQA equipment used, sample of distribution transformer, sampled oil in containers and the BDV machine respectively.

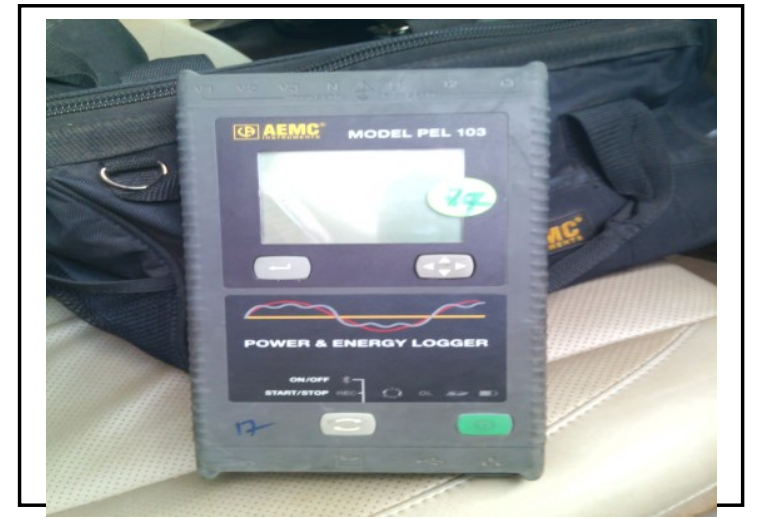

Photo 1a: PQA equipment

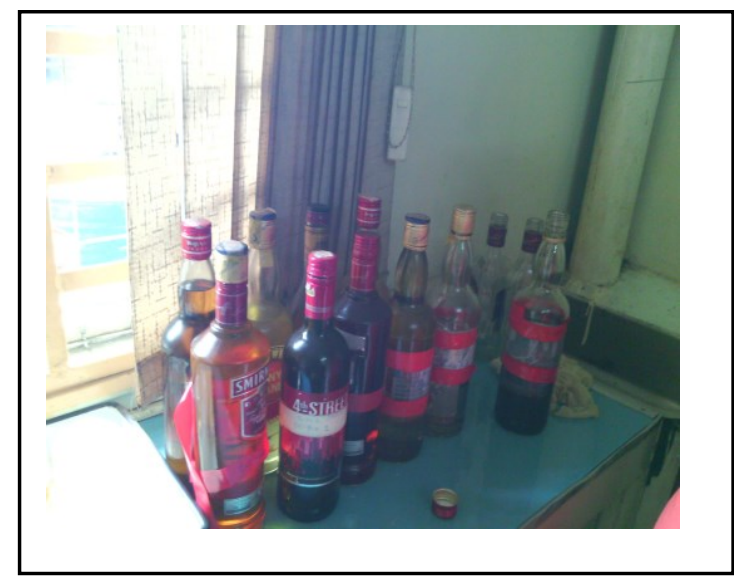

Photo 1c: Sampled transformer oil
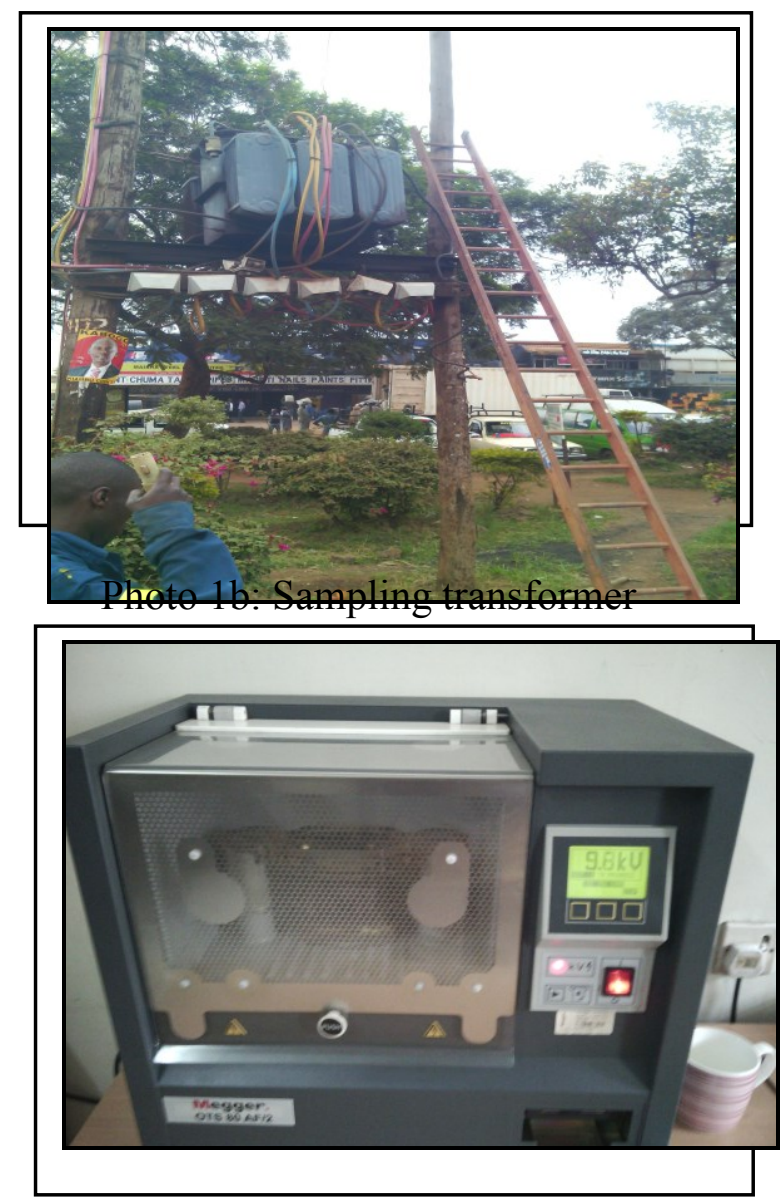

Photo 1d: BDV equipment

Figure 2: The PQA equipment used, sample of distribution transformer, sampled oil in containers and the BDV machine.

\section{RESULTS AND DISCUSSION}

NDUNGU, et al.,: Mitigation of current harmonic distortions streaming from domestic non-linear loads using single phase active power filter. 
Journal of Applied Sciences, Engineering and Technology for Development. Volume 2, Issue 1

The findings of the experiments conducted for various non-linear domestic loads and transformer oil BDV values obtained are presented below. The tables below depict the findings of current harmonic distortions noted on various domestic nonlinear loads. The results obtained are summarized in table 1.

Table 1a: Individual THDi generated

\begin{tabular}{|l|l|l|}
\hline No & Device & THDi \% \\
\hline 1 & TV(CRO) & 93.7 \\
\hline 2 & Video player & 83.51 \\
\hline 3 & TV(Plasma) & 82.15 \\
\hline 4 & Computer- desk top & 80.16 \\
\hline 5 & TV Decoder & 74.53 \\
\hline 6 & Radio & 70.01 \\
\hline 7 & Laptop & 68.01 \\
\hline & $\begin{array}{l}\text { Fluorescence Tube } \\
\text { (F. Tube) }\end{array}$ & 41.61 \\
\hline 9 & Microwave & 34.62 \\
\hline 10 & Fridge & 24.25 \\
\hline
\end{tabular}

Table 1b. Combined loads THDi generated

\begin{tabular}{|r|l|r|}
\hline No & Device & THDi\% \\
\hline 1 & TV (CRO)+Radio & 86.79 \\
\hline 2 & Computer + TV (CRO) & 71.06 \\
\hline 3 & Computer + Radio & 60.08 \\
\hline 4 & TV (CRO)+laptop +F. Tube & 25.34 \\
\hline 5 & TV (CRO)+decoder +F. & 9.43 \\
\hline $\mathbf{6}$ & Tube & $\mathbf{8 . 4 5}$ \\
\hline
\end{tabular}

Table I shows that domestic loads draw current in pulses and hence have distorted waveforms (thus high THDi \%). Among the investigated single phase modern devices, the TV (CROtechnology) was found to generate the highest harmonic distortions as compared to the other types of domestic loads. This could mainly be due to improvement by manufacturers as they try to comply with stringent requirements of various power quality standards such as 610002-3-4 standards that define the recommended harmonic distortions generated by low voltage supplied loads, IEEE 519 -1996, IEC 1000-3-2 and ER G5/4. Further, reduction in total harmonic distortions was evident when more loads were supplied at the same common point as shown in table $1 \mathrm{~b}$. The cancellation effect was a result of phase angle differences of harmonic generated by each individual device. It is worth noting that same loads with similar electric characteristics when connected together have additive harmonic distortions effect while different types of non-linear loads supplied power together have damping effect on the total harmonic distortions as noted by Ming-Yin et al., (2007). This could explain why it is recommended to have different non-linear loads supplied from the same common power supply. The table 2 shows the results on the transformer oil breakdown voltage.

Table 2: Sampled transformer oil BDV and colour results

\begin{tabular}{|l|l|l|l|r|}
\hline $\begin{array}{c}\text { Dominant } \\
\text { loads }\end{array}$ & $\begin{array}{c}\text { Supplying } \\
\text { substation } \\
\text { loads (TX1) }\end{array}$ & $\begin{array}{c}\text { Supplying } \\
\text { commercial } \\
\text { loads (TX2) }\end{array}$ & $\begin{array}{c}\text { Supplying } \\
\text { urban domestic } \\
\text { loads (TX3) }\end{array}$ & $\begin{array}{c}\text { Supplying Rural } \\
\text { domestic loads } \\
\text { (TX4) }\end{array}$ \\
\hline Oil Colour & Brownish & Yellowish & Clear & Clear \\
\hline $\begin{array}{l}\text { BDV AVE } \\
\text { (kV). }\end{array}$ & $\mathbf{7 4}$ & $\mathbf{7 9 . 4}$ & $\mathbf{5 5 . 8}$ & $\mathbf{2 4 . 8}$ \\
\hline (THDi\%) & $\mathbf{1 4 . 0}$ & $\mathbf{1 0 . 2 5}$ & $\mathbf{2 8 . 5 8}$ & $\mathbf{3 8 . 4 0}$ \\
\hline
\end{tabular}

From the findings shown in table 2, it was observed that break down voltage (BDV) was lowest $(24.8 \mathrm{kV})$ on transformer suppling rural domestic loads which had the highest recorded current harmonic distortions (38.40\%). Further, the clear oil colour was noted. Despite TX1

NDUNGU, et al.,: Mitigation of current harmonic distortions streaming from domestic non-linear loads using single phase active power filter. 


\section{Journal of Applied Sciences, Engineering and Technology for Development. Volume 2, Issue 1}

(Supplying substation loads) having brownish oil colour, the BDV was substantially high $(74 \mathrm{kV})$. The colour change could be due to oil ageing as the transformer was the oldest (27 years) in the service. It is imperative to note the recommended transformer oil BDV should be $>30 \mathrm{kV}$ for adequate dielectric insulation of transformer while recommended oil colour is clear or yellowish. It could be deduced that high current harmonics deteriorate dielectric strength of transformer oils. In addition, transformer colour oil changes with ages. The research has shown that the core losses and stray losses significantly elevate the temperature of a transformer and has direct proportionality with the level of harmonic frequencies present. The average life expectancy of the transformers is directly proportional to the life of insulating materials. On steady state power supply, harmonics and variations in frequency are the main factors that accelerate aging of insulation materials (oil and paper cellulose) and hence premature failure of distribution transformers.

\section{CONCLUSION}

There has been unprecedented steady growth of domestic power consumers of which $85 \%$ of the loads are non-linear; generate and inject myriad of harmonic distortions in the power grid. Presence of harmonic distortions result to unsafe and unreliable electrical power supplies, malfunction of equipment, overheating of conductors, reduce efficiency and life of most connected loads. In addition, growing use of sensitive electronic devices and awareness of power end users of reliable and quality power has resulted in engineers researching on methods of reduction system perturbations such as harmonic distortions, transients and power surges. This study proposes the use of single phase shunt active filter at PCC to mitigate current harmonic emanating from domestic non-linear loads. The findings are pertinent to distribution utilities who have the responsibility of maintaining acceptable power quality as stipulated in power quality standards, and to researchers who would seek to model the characteristic of modern domestic non-linear loads.

\section{ACKNOWLEDGMENT}

The authors thank the management and staff of Kenya Power for the supporting this study.

\section{REFERENCES}

Hussein, A. A., El-Metwally, M., and Osama, M. F. (2010). Harmonic distortion effects and mitigation in distribution systems, Journal of American Science, V2, pp 6 -10

Alberto, D., and Sonia L. (2012). Power quality and harmonic analysis of end user devices,' energies, ISSN 1996 - 1073 pp 5453-5464.

Prachi G. (2010). Effect of harmonics on active power flow and apparent power in the power system, IOSR Journal of Mechanical and civil Engineering ISSN: 2278 - 1684, pp 22-26

Ndung'u, C., and Nderu, J. (2012). Mitigation of harmonic distortions and low power factor using active power filter for low voltage power supplies. Proceedings of the Mechanical Engineering Annual Conference on Sustainable Research and Innovation - JKUAT, ISSN 2079-6226.

Sean, E., Phil, C., and Sarath, P. (2001). Supply current characteristic of modern domestic loads, IEEE Transaction on Power Electronic Delivery, Vol.10, pp 1-7

Caramia, P., Russo, M., and Verde, P. (2011) Modelling of Domestic Non-linear Loads for Harmonic Analysis', Proceedings of Domestic use of Electrical Energy Conference. pp 87-95 NDUNGU, et al.,: Mitigation of current harmonic distortions streaming from domestic non-linear loads using single phase active power filter. 
Ming-Yin, C., Ken, K.F. L., and Michael, W. F. (2007). A case study survey of harmonic currents generated from a computer centre in an office building', Architectural Science Review, Vol.50.3 pp. 274-280.

Said, D.M., and NorK, M. (2008). Effects of harmonics on distribution transformers, Proceedings of Australasian Universities Power Engineering Conference. pp 241-248

Peng, F. Z. (2001). Harmonics sources and filtering approaches, IEEE Industrial Magazine, Vol.7, pp. $18-25$

Mehta, V.K. (2010). Principle of power system. Wiley Eastern publisher, New Delhi, 4th Edn

Sobhy, S. D., Khairy, F. S., Yasser, S. A, and Wessam A. H. (2013). Shunt active filter for harmonic mitigation of a resistance spot welding machine', Journal Electrical Engineering Vol.3, pp. $28-35$

Hussein, A. K. (2013). Harmonic mitigation techniques applied to power distribution network', Journal Advance in Power Electronics, Vol.4. 26- 38

Charles, N., John, N., and Livingstone, N. (2012). Effects of compact fluorescence light (CFL) bulbs on power quality', Journal of energy Technology and Policy, ISSN 2224-3232, Vol. 2 No.3 pp 10-15 